\title{
Human Lung Cancer cell line SPC-A1 contains cells with characteristics of cancer stem cells
}

\author{
C. H. ZHOU*, S. F. YANG, P. Q. LI \\ Department of Pathology, Conghua College of Guangzhou Medical University, Guangzhou 510925, China \\ *Correspondence: zchcyxcfy@yahoo.com.cn
}

Received May 6, 2012 / Accepted June 17, 2012

\begin{abstract}
Cancer stem cells (CSCs) play important roles in occurrence, development, recurrence and metastasis of cancer. Isolation and identification of CSCs have been performed from some cancer tissues or cells. In this paper, human lung adenocarcinoma stem cells were induced and isolated from SPC-A1 cells and their characteristics were determined. SPC-A1 cells were cultured in serum-free medium and epidermal growth factor and basic fibroblast growth factor were added into the medium to induce the formation of multicellular tumor spheroids. The results showed that floating multicellular tumor spheroids (named pulmospheres) were formed 5-10 d after the induction of SPC-A1 cells. Real-time PCR analysis showed that in the pulmospheres, the marker of bronchioalveolar stem cells, Clara cell secretary protein and the marker of AT2 cells, alveolar surfactant protein $\mathrm{C}$ were highly expressed. Furthermore, such embryonic stem cell markers as octamer-binding transcription factor 4 (OCT-4), Bmi-1, and thyroid transcription factor -1 (TTF-1) were also highly expressed. Some miRNAs as hsa-miR-126, hsa-miR-145, hsa-let-7g, hsa-let-7d, hsa-let-7c, hsa-let-7e and hsa-miR-98, which were lowly expressed in SPC-A1 cells, were not expressed in the pulmospheres. Cell cycle analysis showed that $94.29 \%$ of the pulmosphere cells were in G1 stages. Further study showed that these cells possessed higher proliferation and invasion activity than SPC-A1 cells. Tumorigenicity activity experiments on BALB/c nude mice showed that $1 \times 10^{3}$ of the pulmosphere cells could form tumors with similar pathological features with lung adenocarcinoma. In conclusion, lung adenocarcinoma stem cells were enriched in the pulmosphere cells and were with high tumorigenicity.
\end{abstract}

Key words: lung adenocarcinoma, SPC-A1, cancer stem cells

Adenocarcinoma is the most common type of lung cancer, which accounts for 20-30\% of all types. Most lung adenocarcinomas originate from smaller bronchial epithelial cells which secret mucus [1]. Based on expression profiles of 293 genes in 90 cases of lung adenocarcinoma, adenocarcinomas were divided into terminal respiratory unit (TRU) type and non-TRU type [2]. TRU-type adenocarcinoma normally originates from Clara cells and alveolar type II cells at the terminal bronchioles, and is characterized by expression of thyroid transcription factor -1 (TTF-1) and lung surfactant protein [3]. While non-TRU-type adenocarcinoma normally originates from bronchial basal cells and mucus-secreting cells.

In the past 20 years, cancer stem cell (CSC) hypothesis stipulated that primary tumors were initiated and maintained by a small subpopulation of cancer cells that possess "stem-like" characteristics [4]. These cells (termed CSCs) are slowly dividing, highly chemoresistant and capable of tumor progression [5]. They play important roles in cancer occurrence, development, recurrence and metastasis [6]. Therefore, identification and control of CSCs are important for the prevention, early detection, diagnosis and treatment of cancers. In 1994, Lapidot et al [7] first identified leukaemia-initiating cells, and other CSCs have been identified from other tissues. However, the CSCs for lung cancer have not been identified till 10 years later. In 2005, at the bronchioalveolar duct junction, Kim et al isolated a stem cell population, termed bronchioalveolar stem cells (BASCs) [8]. BASCs exhibited self-renewal and were multipotent in clonal assays, and expanded in response to oncogenic K-ras in culture and in precursors of lung tumors in vivo. These findings suggested that BASCs formed stem cell population maintaining the bronchiolar Clara cells and alveolar cells of the distal lung and that their transformed counterparts gave rise to adenocarcinoma. Then, Ho et al showed that CSCs of 
lung cancers (including lung adenocarcinoma) were enriched in side population, and that they expressed ATP-binding cassette transporter [9]. However, Eramo's report showed that CSCs of lung cancers were CD $133^{+}$cells [10]. The methods used and the conclusions acquired about the characteristics and origins of adenocarcinoma stem cells are not consistent [8-11]. So separation and identification of adenocarcinoma stem cells remain to be the focus of researches.

In this paper, we acquired monoclonal SPC-A1 cells by using limited dilution method [11]. Then we induced the formation of multicellular tumor spheroids by adding growth factors. To determine whether these multicellular tumor spheroids contained CSCs, expression levels of CSC markers were assayed, and cell cycle analysis performed, and proliferation, invasion and tumorigenicity activity determined.

\section{Materials and methods}

Cells. Lung adenocarcinoma SPC-A1 cell line was purchased from China Center for Type Culture Collection (Wuhan, China), and cultured in RPMI-1640 medium (Gibco) supplemented with $10 \%$ fetal bovine serum (Hyclone).

Acquisition of monoclonal SPC-A1 cells. Preparation of monoclonal cells was performed as Zheng et al [11] with minor modifications. Logarithmic phase cells were digested with $0.25 \%$ trypsin (Gibco) and centrifuged at $200 \mathrm{~g}$ for 5 min. Then the cells were resuspended in RPMI-1640 medium, diluted to 10 cells per $\mathrm{ml}$ and inoculated into wells of 96-well plate with $100 \mu \mathrm{l}$ per well. Twenty-four h later, only the wells with one cell in each well were reserved and cultured for 2 weeks. Then the clones were inoculated into new wells of 96-well plates to generate new clones. Induction of multicellular tumor spheroids. Monoclonal SPC-A1 cells were suspended in DMEM/F12 medium, adjusted to $1 \times 10^{4}$ cells per $\mathrm{ml}$ and inoculated into wells of 24-well plates. Such growth factors as B-27, epidermal growth factor (EGF, $20 \mathrm{ng} / \mathrm{ml}$, PeproTech), basic fibroblast growth factor (bFGF, $10 \mathrm{ng} / \mathrm{ml}$, PeproTech), and methyl cellulose (MC, $0.8 \%$, Sigma) were added into the medium. The cells were cultured till the formation of multicellular tumor spheroids. Then the first generation of multicellular tumor spheroids were digested and inoculated into new wells till the formation of second and third generations of spheroids.

Quantitative RT-PCR analysis. Cells were collected and RNA isolated by using Trizol reagent (Gibco). $1 \mu \mathrm{g}$ of RNA was reverse transcripted to cDNAs which were suitable for quantitative RT-PCR analysis by using ExScript RT-PCR kit (Takara, Japan). Oligonucleotide primers for OCT4, CCSP, SP-C, Bmi-1, TTF-1, ABCG2 and GAPDH quantitative RTPCR were designed according to their sequences (Table 1). All amplification and detection were carried out using cDNAs described above and ExScript SYBR green QPCR kit (Takara, Japan) in the Applied Biosystems Prism 7000 system (Foster City, CA). The program is as follow: $95^{\circ} \mathrm{C} / 5$ min, 1 cycle; $95^{\circ} \mathrm{C} / 15 \mathrm{~s}, 55^{\circ} \mathrm{C} / 30 \mathrm{~s}, 72{ }^{\circ} \mathrm{C} / 30 \mathrm{~s}, 40$ cycles, followed by a $30 \mathrm{~min}$ dissociation curve collection for verifying the primer dimers. For the detection of miRNAs, $5 \mu \mathrm{g}$ of RNA was polyadenylated at $37^{\circ} \mathrm{C}$ for 20 min by poly (A) polymerase. Primers for mature hsa-miR-126, hsa-miR-145, hsa-let-7g, hsa-let-7d, hsa-let-7c, hsa-let-7e, hsa-miR-98 and U6 were purchased from Ambion Company, with U6 snRNA as the internal control.

Cell cycle assay. $1 \times 10^{6}$ of cells in logarithmic growth phase were centrifugated at $300 \mathrm{~g}$ for $5 \mathrm{~min}$, washed with cold phosphate-buffered saline (PBS) twice and resuspended in 3 $\mathrm{ml}$ of ice-cold $70 \%$ ethanol overnight. Then the suspension was centrifugated at $300 \mathrm{~g}$ for $5 \mathrm{~min}$, washed with cold PBS twice and resuspended in $1 \mathrm{ml}$ of $50 \mu \mathrm{g} / \mathrm{ml}$ propidium iodide solution for staining at dark at $4{ }^{\circ} \mathrm{C}$ for $30 \mathrm{~min}$. Then $10 \mu \mathrm{g} / \mathrm{ml}$ of RNaseA was added into the suspension and cycle distribution was measured by flow cytometry.

Cell proliferation assay. MTT (4, 5-demethylthiazol-2, 5-diphenyl-2H-tetrazolium bromide) method was used to as-

Table 1 Primers for real-time PCR

\begin{tabular}{llcc}
\hline Primer & \multicolumn{1}{c}{ Sequence (5' -3') $^{\prime}$ Product size (bp) } & Acce. No. \\
\hline OCT4-F & GTGAGAGGCAACCTGGAG & 111 & NM_002701 \\
OCT4-R & CCACACTCGGACCACATC & & \\
CCSP-F & AGCCCAGAGAAAGCATCATTAAGC & 114 & NM_003357 \\
CCSP-R & AGCATGGCAGCGGCAGAG & & \\
SP-C-F & GTGGTGGTGGTCCTCATC & 101 & NM_003018 \\
SP-C-R & CCAATGCTCATCTCCAGAAC & & \\
Bmi-1-F & AAATGCTGGAGAACTGGAAAG & 126 & NM_005180 \\
Bmi-1-R & AACTGTGGATGAGGAGACTG & & \\
TTF-1-F & GGAGATGCCGATGATTCAGATG & 102 & NM_007344 \\
TTF-1-R & CCGCTTGATTGTGCTGGTG & & \\
ABCG2-F & CTCTTCTTCCTGACGACCAACC & 113 & NM_004827 \\
ABCG2-R & GACACTCTGTAGTATCCGCTGATG & & \\
GAPDH-F & TCTCTGCTCCTCCTGTTC & 97 & NM_002046 \\
GAPDH-F & ACTCCGACCTTCACCTTC & & \\
\hline
\end{tabular}


say the proliferation activity of SPC-A1 and the pulmosphere cells. The cells were cultured to $70 \%$ surface of the well of 6well plates, collected and numbered, and $2.5 \times 10^{3}$ cells were seeded into each well of 96-well plates. Then MTT values of wells were determined each day and proliferation curve was prepared.

Transwell invasion assay. Wells of $8 \mu \mathrm{m}$ pore size Transwell plates (Corning, USA) were coated with $30 \mu$ of diluted Matrigel and incubated at $37^{\circ} \mathrm{C}$ for $30 \mathrm{~min}$ for solidification. Wells of 24-well plates were added $750 \mu$ of DMEM/F12 medium supplemented with $10 \%$ FBS. Then the wells of Transwell plates were placed into the wells of 24 -well plates. $500 \mu \mathrm{l}$ of the cells (adjusted to $3 \times 10^{5} / \mathrm{ml}$ ) were added into the Transwell wells. After incubation at $37^{\circ} \mathrm{C}$ for $48 \mathrm{~h}$, the Transwell wells were removed. The cells crossed through the Matrigel into the wells were fixed with methanol. Then $1 \mathrm{ml}$ of $3 \%$ acetic acid was added to disrupt the cells and the absorbance was measured at $570 \mathrm{~nm}$ wavelength.

Determination of tumorigenic activity in nude mice. Cells which were harvested by trypsinization and adjusted to proper concentration in PBS were injected at a single subcutaneous site at left armpit into each 4 week-old nude mouse (BALB / c, Experimental Animal Center of Sun Yat-Sen University). All mice were examined regularly for development of tumors till the tumor diameter was more than $1 \mathrm{~cm}$ or the experiment period reached $60 \mathrm{~d}$. The mice were sacrificed by cervical method and the tumors were removed. Part of tumor tissue was fixed with formalin and embedded in paraffin. Paraffin sections were used for HE staining.

Statistical analysis. All analyses were performed using the SPSS17.0 software. Quantitative data were presented as mean \pm SD. Differences between means were evaluated by analysis of variance of factorial design for cell proliferation, cell cycle and invasion assay, while by one-factor analysis of variance (one-way ANOVA) for fluorescence quantitative PCR. P $<0.05$ was considered statistically significant.

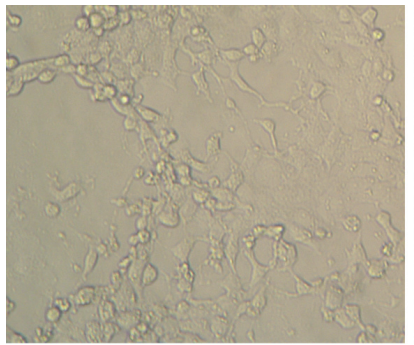

A

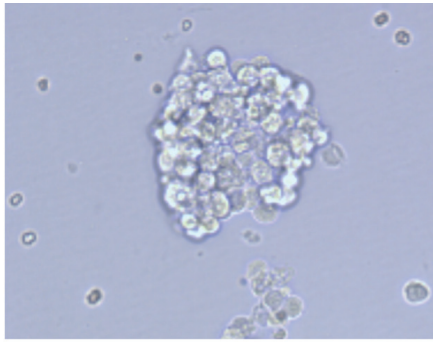

B
Figure 1. Cultured cells. A. SPC-A1 cells; B. pulmosphere cells. Monoclonal SPC-A1 cells were adjusted to $1 \times 10^{4}$ cells per $\mathrm{ml}$ and inoculated into wells of 24-well plates. Such growth factors as B-27, epidermal growth factor (EGF, $20 \mathrm{ng} / \mathrm{ml}$, PeproTech), basic fibroblast growth factor (bFGF, $10 \mathrm{ng} / \mathrm{ml}$, PeproTech), and methyl cellulose (MC, 0.8\%, Sigma) were added into the medium for the induction of the multicellular tumor spheriods.

\section{Results}

Formation of lung adenocarcinoma multicellular tumor spheroids 5-10 d after the induction of monoclonal SPC-A1 cells in serum-free medium using EGF and bFGF, multicellular tumor spheroids formed and they were named pulmospheres (Fig. 1). The cells could grow in serum-free medium, which suggested that they possessed self sufficiency for growth signaling, an important characteristic of stem cells [12].

Expression of stem cell markers RT-PCR analysis showed SP-C, the marker of type II alveolar epithelial cells (AT2), was expressed in the SPC-A1 cells (Fig.2). This suggested that SPC-A1 cells belong to AT2 cell. Further results showed CCSP, the marker of BASC cells, and OCT-4, the marker of ESC, expressed lowly in the SPC-A1 cells. However, CCSP, OCT4 and Bmi-1 were highly expressed in the pulmosphere cells. This suggested that CSCs were enriched in the pulmospheres.
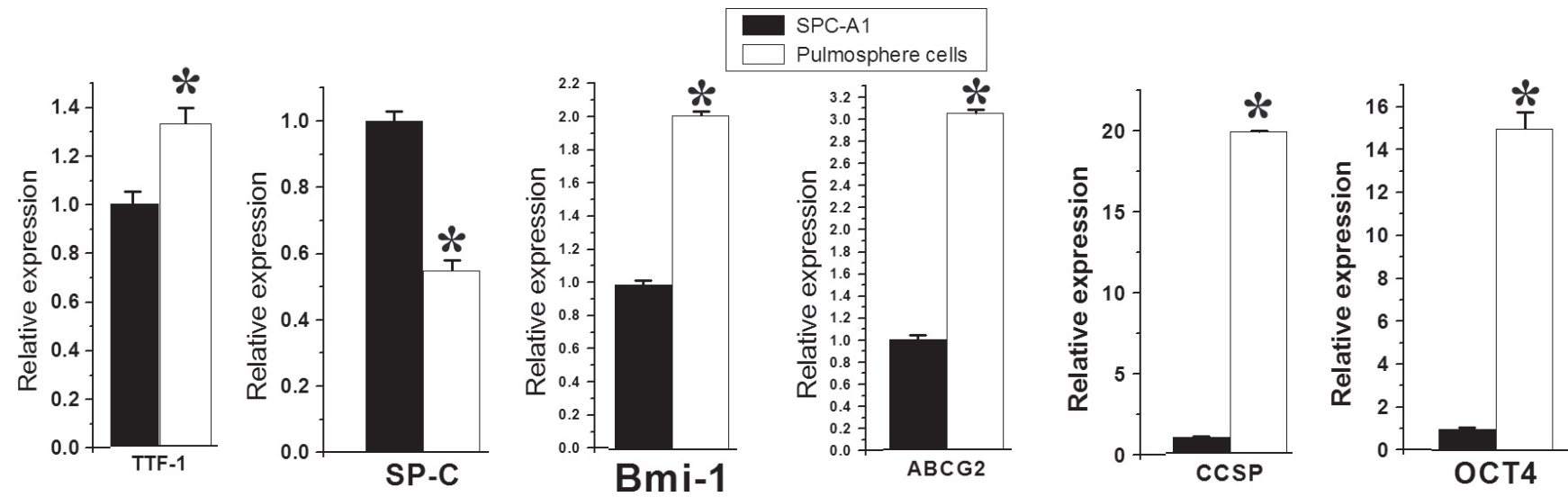

Figure 2. Expression of stem cell markers in SPC-A1 cells and pulmosphere cells by using real-time quantitative PCR. GAPDH served as a loading control. Each bar represents the mean \pm SD from three samples, ${ }^{*}$ showed significant differences between the SPC-A1 cells and pulmosphere cells $(\mathrm{P}<0.05)$. 


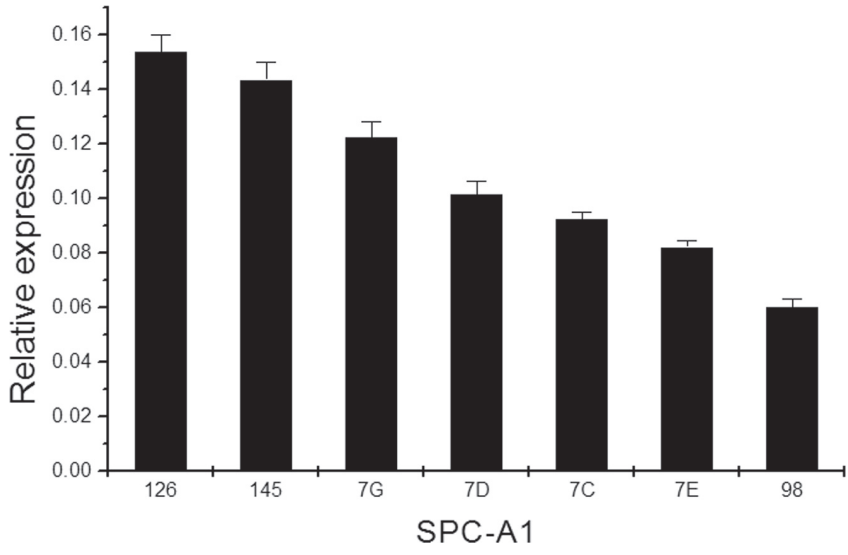

Figure 3. Expression of some miRNAs in SPC-A1 cells by using real-time quantitative PCR. U6 snRNA served as the internal control. Each bar represents the mean \pm SD from three samples.

miRNA expression Such miRNAs as hsa-miR-126, hsa-miR145, hsa-let-7g, hsa-let-7d, hsa-let-7c, hsa-let-7e and hsa-miR-98 were reported to express lowlier in lung adenocarcinoma tissues than in normal tissues, and not to express in CSCs [13-18]. RTPCR analysis showed that these miRNAs were lowly expressed in SPC-A1 cells (Fig. 3), and not expressed in the pulmosphere cells (Data not shown). This suggested that the pulmosphere cells possessed similar characteristics with CSCs.

Cell cycle and cell proliferation activity Flow cytometry study showed that fractions of G1, G2 and S phase of pulmosphere cells were $94.29 \%, 2.26 \%$ and $3.45 \%$, respectively, while those of SPC-A1 cells were $51.97 \%, 14.15 \%$ and 33.88 $\%$, respectively (Fig. 4). SPC-A1 and the pulmosphere cells were seeded in the wells of 96-well plates in the same concentrations and the proliferation curves were prepared using MTT method. The results showed that the pulmosphere cells possessed higher proliferation activity than the SPC-A1 cells $(\mathrm{P}<0.01)$ (Fig. 5)

Cell invasion activity Transwell invasion assays showed that few SPC-A1 cells cultured in DMED/F12 medium supplemented with $10 \% \mathrm{FBS}$ and $100 \mathrm{ng} / \mathrm{ml}$ of IGF21 could cross Matrigel. However, much more pulmosphere cells (10 times as the SPC-A1 cells) could cross Matrigel and fall into the wells of 24-well plates (Fig. 6). This suggested that pulmosphere cells possessed higher invasion activity than the SPC-A1 cells.

Tumorigenicity of the pulmosphere cells Tumorigenicity activity assay showed that transplantation of $1 \times 10^{5} \mathrm{SPC}-\mathrm{A} 1$ cells could induce tumor in nude mice. In the same condition, $1 \times 10^{3}$ pulmosphere cells could induce larger tumor than SPC-A1 cells (Fig. 7). Further HE staining showed that the histological and pathological features were the same as the tumor induced by SPC-A1 cells (Fig. 8). This suggested that the tumorigenicity of the pulmosphere cells were 100 times as the SPC-A1 cells.

\section{Discussion}

In recent years, the incidence of lung cancer has increased, and non-small cell lung cancers (NSCLC) account for $80 \%$ of lung cancers. Lung adenocarcinoma is the main type of NSCLC, and its incidence has also increased in these years. So identifying the origin cells of lung adenocarcinoma and the tumorigenicity mechanism have become more and more important. As we know, cancer stem cells play important roles

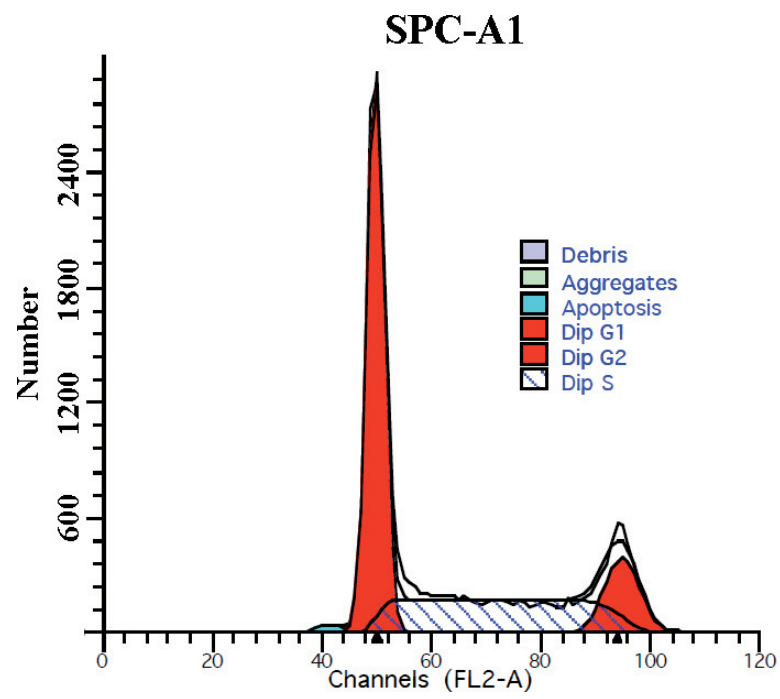

\section{Pulmosphere cells}

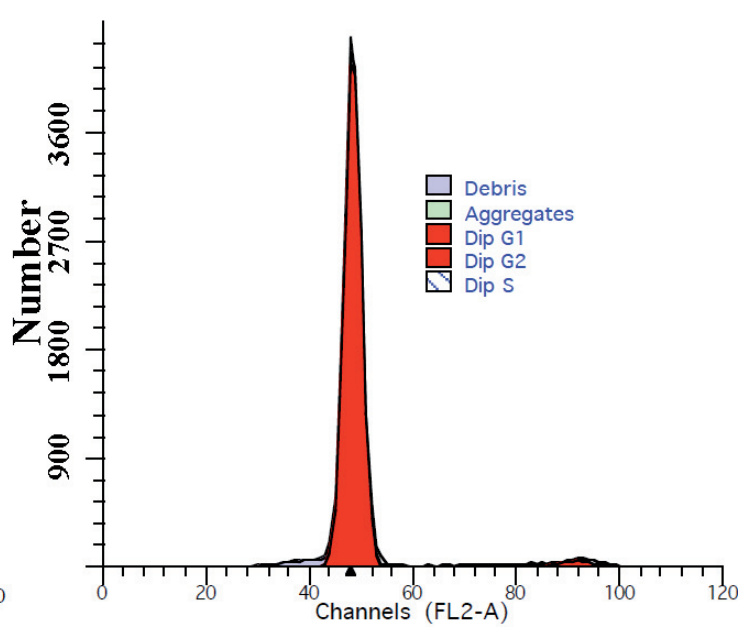

Figure 4. Cell cycle analysis of SPC-A1 and pulmosphere cells was measured by flow cytometry. Cells in logarithmic growth phase were centrifugated, washed with cold PBS twice and resuspended in ice-cold $70 \%$ ethanol overnight. Then the suspension was centrifugated, washed with cold PBS twice and resuspended in propidium iodide solution for staining at dark at $4{ }^{\circ} \mathrm{C}$ for $30 \mathrm{~min}$. Then RNaseA was added into the suspension and cycle distribution was measured by flow cytometry. 


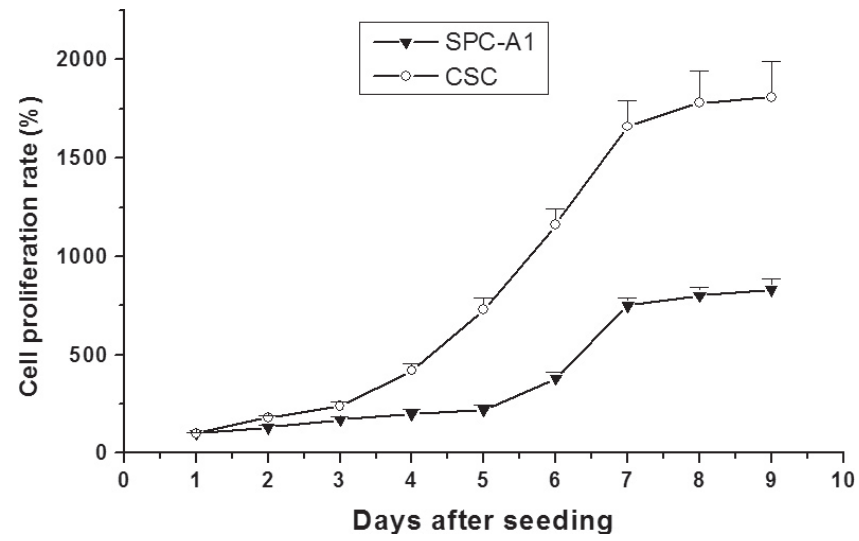

Figure 5. Proliferation curve of SPC-A1 cells and pulmosphere cells by MTT. Cells were collected and numbered, and $2.5 \times 10^{3}$ cells were seeded into each well of 96-well plates. Then MTT values of wells were determined each day and proliferation curve was prepared.

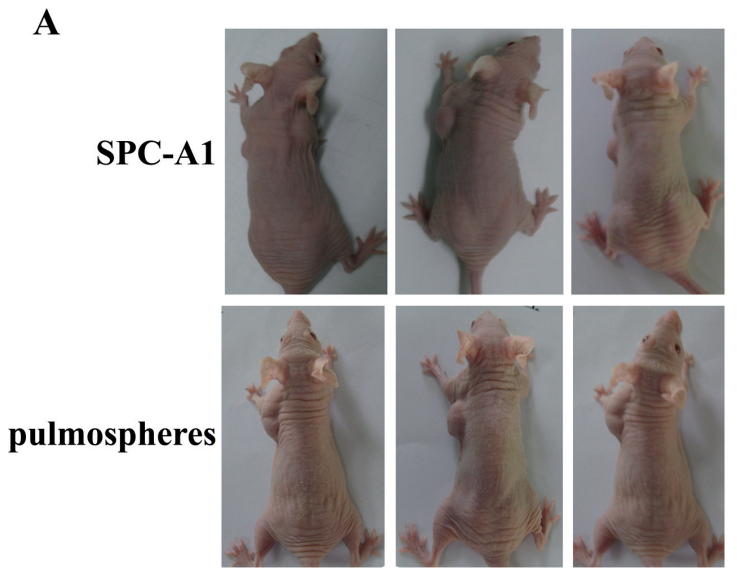

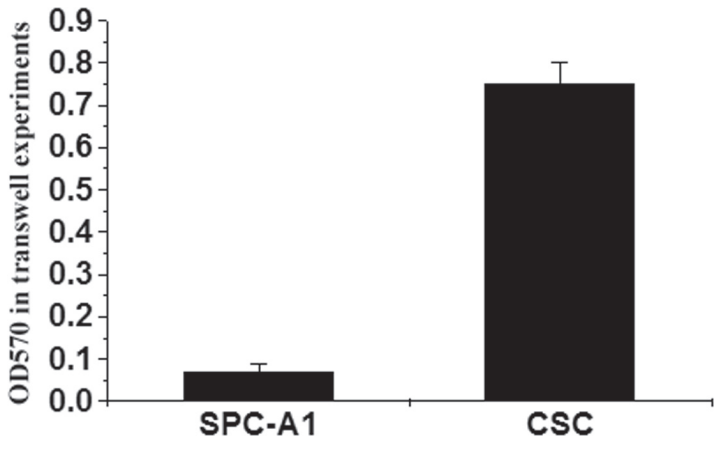

Figure 6. Invasion activity of SPC-A1 cells and pulmosphere cells by Transwell invasion assay. Cells (adjusted to $3 \times 10^{5} / \mathrm{ml}$ ) were added into pretreated Transwell wells which were placed in the wells of 24-well plates. After incubation for $48 \mathrm{~h}$, the Transwell wells were removed. The cells crossed through the Matrigel into the wells were fixed with methanol. Then $3 \%$ acetic acid was added to disrupt the cells and the absorbance was measured at $570 \mathrm{~nm}$ wavelength.

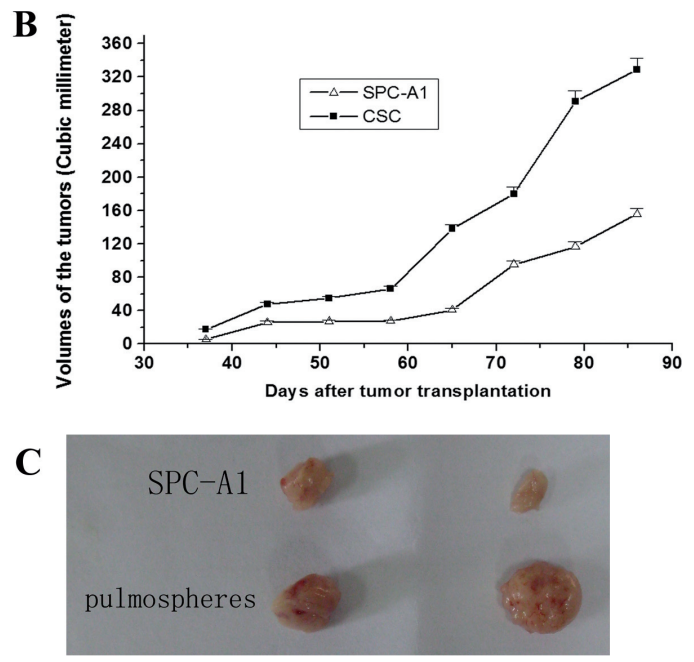

Figure 7. Analysis of tumorigenicity. A: mice transplanted with SPC-A1 cells and pulmosphere cells. Harvested cells were adjusted to proper concentration in phosphate-buffered saline (PBS) and injected at a single subcutaneous site at left armpit into each 4-week old nude BALB/c mouse. B: The volumes of tumors after transplantation. C: the tumors dissected from transplanted mice.
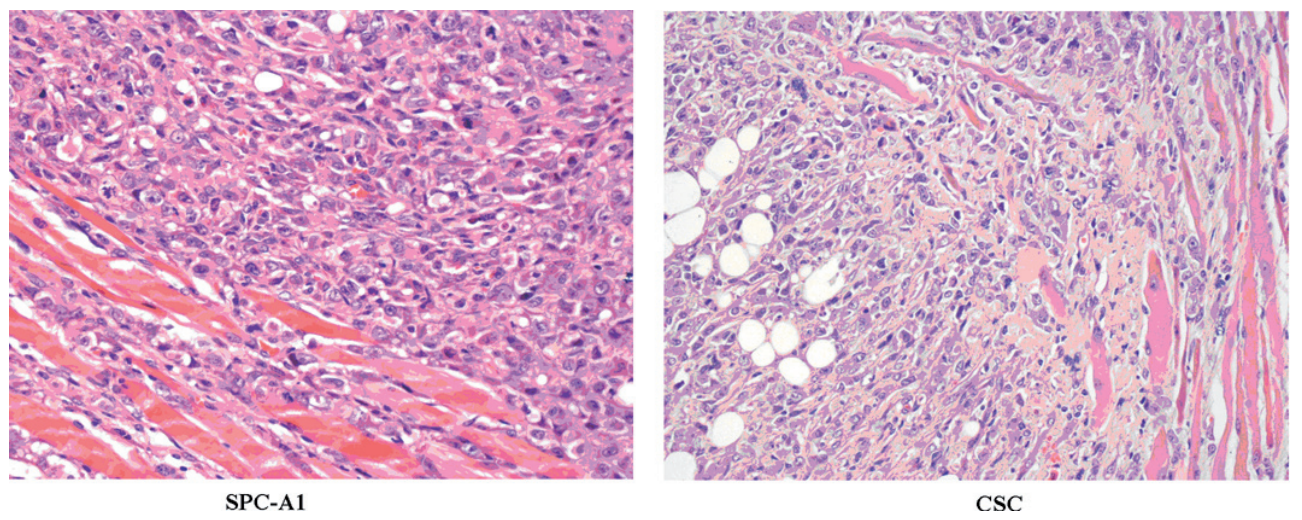

Figure 8. H.E. staining of the transplanting tumors $($ H.E. $\times 400)$. The tumor cells were in shapes as nest and they invaded surrounding tissues. The tumor cells showed different types with normal cells. The nucleus were large and in round or oval shapes with apparent nucleolus and obvious mitotic phenomena. 
in the formation, development, recurrence and metastasis of many types of cancers [4-6]. Thus, isolation and identification of lung cancer stem cells is important for exploring effective measures for curing lung adenocarcinoma. In 2005, bronchioalveolar stem cells and mesenchymal stem cells have been identified from mouse lung [8]. In 2007, Ho et al [9] showed that side population cells of human lung cancer cell lines possessed higher tumorigenicity than the non side population cells, which suggested that the side population cells showed characteristics of stem cells.

Three methods were normally used to isolate cancer stem cells. One is based on specific surface markers; the second is based on the SP phenotype; the third is induction using growth factors in serum free medium. It was reported that CSCs of glioma, breast cancer, colon cancer, pancreatic cancer, prostate cancer and melanoma could form multicellular tumor spheroids by the serum-free culture method [19]. Using this method, CSC-rich multicellular tumor spheroids have been acquired from non-small cell lung cancer cell lines (H460 and A549) [20] and human lung cancer tissues [10,21].

In this paper, lung adenocarcinoma cell line SPC-A1 was induced in serum-free medium by EGF, bFGF and B27, and multicellular tumor spheroids formed. Further RT-PCR analysis showed that some CSC markers were expressed in these pulmosphere cells, and tumorigenicity assay showed that these cells possessed high tumorigenicity activity. The results suggested that EGF and bFGF induction is an effective method to obtain CSCs of lung cancer.

Some proteins have been used as lung cancer CSC markers. Most lung cancer cells express Clara cell secretary protein (CCSP), the marker of Clara cell, and surfactant protein C (SP-C), the marker of alveolar type II (AT2) [22]. OCT4 forms transcription factor complex with Sox 2 and Nanog and regulates the expression of 2260 genes engaged in chromatin conformation, DNA repair, cell proliferation and apoptosis. Thus it is an important regulation factor for self-renewal of stem cells and is a well-known CSC marker [23-24]. Meanwhile, Bmi-1 provides unlimited proliferation activity to CSC through regulation of telomerase reverse transcriptase and tumor suppressor gene P16INK4, thus is regarded as an important CSC marker [24-25]. TTF-1 was mainly expressed in terminal respiratory units such as alveolar epithelium cells and bronchial epithelial cells, thus it was the marker of normal cells or tumors of terminal respiratory units [26]. In most cases of lung adenocarcinoma, tumor cells differentiate to Clara cells or type II alveolar epithelial cells, so TTF-1 was expressed in most cases of adenocarcinoma, and was widely used for the differential diagnosis of lung adenocarcinomas [26]. ABCG2 is an important marker for hematopoietic stem cells, and has been used to isolate stem cells or CSCs [27]. In this paper, to evaluate the stem cell characteristics of the pulmosphere cells, real time RT-PCR was used to assay the expression of above mentioned markers of lung adenocarcinoma and stem cells. The results showed that OCT4 was expressed in low level in SPC-A1 cells, while the expression level increased dramatically in the pulmosphere cells. Furthermore, the high expression of Bmi-1 gene in the pulmosphere cells suggested their characteristics of embryonic stem cells. The pulmosphere cells also expressed markers of lung stem cells such as CCSP, SP-C, and TTF-1, which was similar to mouse BASC. These results suggested that the pulmosphere cells may be the CSCs of lung adenocarcinoma.

Many miRNAs were reported to be related with the development of tumors and differentiation of stem cells [28]. For example, let-7 was not expressed in human and mouse embryonic stem cells. However, with the differentiation of the stem cells, the expression of let-7 increased. Furthermore, the expression level of let-7 was much lower in many tumor tissues than in normal tissues [29]. It was reported that let-7 could inhibit caspase-3 activity and inhibit cell apoptosis, and negatively regulated expression of oncogenes such as Ras, HMGA2 and c-Mys, and cell cycle regulation factors such as CDC25A, CDK6 and CyclinD2 [29]. Thus let-7 was suggested to inhibit proliferation of cells, while enhance cell differentiation and apoptosis. Another miRNA, hsa-miR-145, could inhibit proliferation of stem cells of lung carcinoma cell line A549 by negatively regulating the expression of OCT4 [30]. The expression of hsa-miR-145 is normally low in adenocarcinoma, and transfection of hsa-miR-145 into adenocarcinoma cells could enhance apoptosis of the cells, especially those with EGFR gene mutation [17]. Furthermore, in non-small cell lung cancers, hsa-miR-126 inhibited cell adhesion, proliferation and metastasis through regulation of VEGF, which was involved in intracellular signal transduction pathway [14]. These results suggested that hsa-miR-126 possessed anti-cancer activity. In this study, we examined the expression of these mentioned miRNAs in the pulmosphere cells and the results showed that hsa-miR-126, hsa-miR-145, hsa-let-7g, hsa-let-7d, hsa-let-7c, hsa-let-7e and hsa-miR-98, which were with low expression levels in SPC-A1 cells, were not expressed in the pulmosphere cells. These results suggested that the pulmosphere cells possessed the characteristics of stem cells.

Furthermore, cell cycle analysis, cell proliferation and invasion assay were performed for the pulmosphere cells. Cell cycle analysis showed that $94.29 \%$ of the pulmosphere cells were in G1 phase, which was much higher than $51.97 \%$ of SPC-A1 cells. This result fit with the fact that most CSCs were in resting stage [31]. In the mean time, the proliferation and invasion activity of pulmosphere cells were apparently higher than those of SPC-A1 cells, which were the important characteristics of CSCs [4-5].

Tumorigenic activity is important method for identification of stem cells [32]. In this study, tumor formation experiments in nude mice showed that the obtained spherical cells had high tumorigenic activity, and further HE staining showed that the tumors showed the same pathological morphology with tumors formed by SPC-A1 cells.

In summary, by using serum-free method, we obtained pulmosphere cells which possessed characteristics of cancer stem cells. 


\section{References}

[1] MORI M, RAO SK, POPPER HH, CAGLE PT, FRAIRE AE. Atypical adenomatous hyperplasia of the lung: a probable forerunner in the development of adenocarcinoma of the lung. Mod Pathol 2001; 14: 72-84. http://dx.doi.org/10.1038/ modpathol.3880259

[2] TAKEUCHI T, TOMIDA S, YATABE Y, KOSAKA T, OSADA $\mathrm{H}$, et al. Expression profile-defined classification of lung adenocarcinoma shows close relationship with underlying major genetic changes and clinicopathologic behaviors. J Clin Oncol 2006; 24: 1679-1688. http://dx.doi.org/10.1200/ LCO.2005.03.8224

[3] YATABE Y, MITSUDOMI T, TAKAHASHI T. TTF-1 expression in pulmonary adenocarcinomas. Am J Surg Pathol 2002; 26: 767-773. http://dx.doi.org/10.1097/00000478-200206000$\underline{00010}$

[4] REYA T, MORRISON SJ, CLARKE MF, WEISSMAN IL. Stem cells, cancer, and cancer stem cells. Nature 2001; 414: 105-111. http://dx.doi.org/10.1038/35102167

[5] CLARKE MF, DICK JE, DIRKS PB, EAVES CJ, JAMIESON $\mathrm{CH}$, et al. Cancer stem cells--perspectives on current status and future directions: AACR Workshop on cancer stem cells. Cancer Res 2006; 66: 9339-9344.

[6] CROKER AK, ALLAN AL. Cancer stem cells: implications for the progression and treatment of metastatic disease. J Cell Mol Med 2008; 12:374-390. http://dx.doi.org/10.1111/j.15824934.2007.00211.x

[7] LAPIDOT T, SIRARD C, VORMOOR J, MURDOCH B, HOANG T, et al. A cell initiating human acute myeloid leukaemia after transplantation into SCID mice. Nature 1994; 367: 645-8. http://dx.doi.org/10.1038/367645a0

[8] KIM CF, JACKSON EL, WOOLFENDEN AE, LAWRENCE S, BABAR I, et al. Identification of bronchioalveolar stem cells in normal lung and lung cancer. Cell 2005; 121: 823-835. http://dx.doi.org/10.1016/j.cell.2005.03.032

[9] HO MM, NG AV, LAM S, HUNG JY. Side population in human lung cancer cell lines and tumors is enriched with stem-like cancer cells. Cancer Res 2007; 67: 4827-4833. http://dx.doi.org/10.1158/0008-5472.CAN-06-3557

[10] ERAMO A, LOTTI F, SETTE G, PILOZZI E, BIFFONI M, et al. Identification and expansion of the tumorigenic lung cancer stem cell population. Cell Death Differ 2008; 15: 504-514. http://dx.doi.org/10.1038/sj.cdd.4402283

[11] ZHENG X, SHEN G, YANG X, LIU W. Most C6 cells are cancer stem cells: evidence from clonal and population analyses. Cancer Res 2007; 67: 3691-3697. http://dx.doi. org/10.1158/0008-5472.CAN-06-3912

[12] LI L, NEAVES WB. Normal stem cells and cancer stem cells: the niche matters. Cancer Res 2006; 66: 4553-4557. http:// dx.doi.org/10.1158/0008-5472.CAN-05-3986

[13] YANAIHARA N, CAPLEN N, BOWMAN E, SEIKE M, KUMAMOTO K, et al. Unique microRNA molecular profiles in lung cancer diagnosis and prognosis. Cancer Cell 2006; 9: 189-198. http://dx.doi.org/10.1016/j.ccr.2006.01.025

[14] CRAWFORD M, BRAWNER E, BATTE K, YU L, HUNTER MG, et al. MicroRNA-126 inhibits invasion in non-small cell lung carcinoma cell lines. Biochem Biophy Res Commun 2008; 373: 607-612. http://dx.doi.org/10.1016/ j.bbrc. 2008.06.090

[15] LIU B, PENG XC, ZHENG XL, WANG J, QIN YW. MiR126 restoration downregulate VEGF and inhibit the growth of lung cancer cell lines in vitro and in vivo. Lung Cancer 2009; 66: 169-175. http://dx.doi.org/10.1016/ j.lungcan.2009.01.010

[16] XU N, PAPAGIANNAKOPOULOS T, PAN G, THOMSON JA, KOSIK KS. MicroRNA-145 regulates OCT4, SOX2, and KLF4 and represses pluripotency in human embryonic stem cells. Cell 2009; 137: 647-658. http://dx.doi.org/10.1016/ j.cell.2009.02.038

[17] CHO WC,CHOW AS, AU JS. Restoration of tumour suppressor hsa-miR-145 inhibits cancer cell growth in lung adenocarcinoma patients with epidermal growth factor receptor mutation. Eur J Cancer 2009; 45: 2197-2206. http://dx.doi. org/10.1016/j.ejca.2009.04.039

[18] KUMAR MS, ERKELAND SJ, PESTER RE, CHEN CY, EBERT MS, et al. Suppression of non-small cell lung tumor development by the let-7 microRNA family. Proc Natl Acad Sci U S A 2008; 105: 3903-3908. http://dx.doi.org/10.1073/ pnas.0712321105

[19] MIMEAULT M, HAUKE R, MEHTA PP, BATRA SK. Recent advances in cancer stem/progenitor cell research: therapeutic implications for overcoming resistance to the most aggressive cancers. J Cell Mol Med 2007; 11: 981-1011. http://dx.doi. org/10.1111/j.1582-4934.2007.00088.x

[20] LEVINA V, MARRANGONI A, WANG T, PARIKH S, SU Y, et al. Elimination of human lung cancer stem cells through targeting of the stem cell factor-c-kit autocrine signaling loop. Cancer Res 2010; 70: 338-346. http://dx.doi.org/10.1158/ 0008-5472.CAN-09-1102

[21] BERTOLINI G, ROZ L, PEREGO P, TORTORETO M, FONTANELLA E, et al. Highly tumorigenic lung cancer CD133+ cells display stem-like features and are spared by cisplatin treatment. Proc Natl Acad Sci U S A 2009; 106: 16281-16286. http://dx.doi.org/10.1073/pnas.0905653106

[22] REYNOLDS SD, HONG KU, GIANGRECO A, MANGO GW, GURON C, et al. Conditional clara cell ablation reveals a self-renewing progenitor function of pulmonary neuroendocrine cells. Am J Physiol Lung Cell Mol Physiol 2000; 278: L1256- L1263.

[23] KAROUBI G, CORTES-DERICKS L, GUGGER M, GALETTA D, SPAGGIARI L, et al. Atypical expression and distribution of embryonic stem cell marker, OCT4, in human lung adenocarcinoma. J Surg Oncol 2010; 102: 689-698. http://dx.doi. org/10.1002/jso.21665

[24] ZHANG XY, DONG QG, HUANG JS, HUANG AM, SHI CL, et al. The expression of stem cell-related indicators as a prognostic factor in human lung adenocarcinoma. J Surg Oncol 2010; 102: 856-862. http://dx.doi.org/10.1002/jso.21718

[25] DOVEY JS, ZACHAREK SJ, KIM CF, LEES JA. Bmi1 is critical for lung tumorigenesis and bronchioalveolar stem cell expansion. Proc Natl Acad Sci U S A 2008; 105: 11857-11862. http://dx.doi.org/10.1073/pnas.0803574105 PMid:18697930 PMCid:2575250 
[26] TANAKA H, YANAGISAWA K, SHINJO K, TAGUCHI A, MAENO K, et al. Lineage-specific dependency of lung adenocarcinomas on the lung development regulator TTF-1. Cancer Res 2007; 67: 6007-6011. http://dx.doi.org/10.1158/00085472.CAN-06-4774

[27] SINGH A, WU H, ZHANG P, HAPPEL C, MA J, et al. Expression of ABCG2 (BCRP) is regulated by Nrf2 in cancer cells that confers side population and chemoresistance phenotype. Mol Cancer Ther 2010; 9: 2365-2376. http://dx.doi. org/10.1158/1535-7163.MCT-10-0108

[28] IORIO MV, CROCE CM. MicroRNAs in cancer: small molecules with a huge impact. J Clin Oncol 2009; 27: 5848-5856. http://dx.doi.org/10.1200/JCO.2009.24.0317
[29] BUSSING I, SLACK FJ, GROSSHANS H. let-7 microRNAs in development, stem cells and cancer. Trends Mol Med 2008; 14: 400-409. http://dx.doi.org/10.1016/j.molmed.2008.07.001

[30] ZHANG S, WU Y, FENG D, ZHANG Z, JIANG F, YIN R, XU L. miR-145 Inhibits Lung Adenocarcinoma Stem Cells Proliferation by Targeting OCT4 Gene. Chinese Journal of Lung Cancer. 2011; 14(4): 317-22.

[31] VELASCO-VELAZQUEZ MA, YU Z, JIAO X, PESTELL RG. Cancer stem cells and the cell cycle: targeting the drive behind breast cancer. Expert Rev Anticancer Ther 2009; 9: 275-9. http://dx.doi.org/10.1586/14737140.9.3.275

[32] LOBO NA, SHIMONO Y, QIAN D, CLARKE MF. The biology of cancer stem cells. Annu Rev Cell Dev Biol 2007; 23: 675-699. 